\title{
PERAN ARTIFICIAL INTELLIGENCE DALAM TAHAP PERENCANAAN DAN PERANCANGAN DESAIN ARSITEKTUR
}

\author{
Andrey Caesar Effendi ${ }^{12 *}$, Prasasto Satwiko ${ }^{3}$ \\ 1. Program studi Arsitektur, Fakultas Seni, Desain, dan Humaniora, Universitas Matana, Kota Tangerang \\ 2. Program studi Doktor Arsitektur Digital, Fakultas Arsitektur dan Desain, Universitas Katolik Soegijapranata, \\ Semarang \\ 3. Program Studi Arsitektur, Universitas Atmajaya Yogyakarta
}

*Correspondent Author: alamat email

Tgl masuk naskah: 13-08-2021 • Tgl review I: 17 \& 18-08-2021 • Tgl revisi: 20-08-2021• Tgl review II: 23 \& 25-08-2021

Tgl terbit 06-09-2021

DOI: 10.24167/joda.v1i1.3682

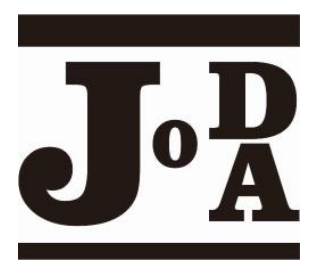

\begin{abstract}
Abstrak: Perkembangan teknologi informasi di masa modern ini menyetuh setiap sendi-sendi kehidupan yang membuat segalanya menjadi lebih mudah dan praktis. Situasi ini juga menggambarkan apa yang terjadi dalam bidang arsitektur yang menuntut peningkatan kompleksitas desain yang lenih tinggi dengan waktu yang lebih cepat dari masa-masa sebelumnya. Penggunaan teknologi digital di masa modern dalam bidang arsitektur perlahanlahan mulai menggeser cara-cara tradisional dalam proses perencanaan dan perancangan arsitektur. Tulisan ini bertujuan untuk mengkaji peran teknologi digital dengan menggunakan Artificial Intellegence dalam proses perencanaan dan perancangan arsitektur di masa kini sehingga menjadikan proses desain menjadi lebih cepat, mudah, dan praktis serta memberikan pilihan-pilihan yang lebih beragam bagi arsitek untuk menentukan keputusan desain. Metode yang digunakan dalam penulisan ini adalah dengan menganalisa literature dari beberapa penelitian terkait tentang teori perencanaan dan perancangan serta serta Artificial Intellegence. Dengan perkembangan yang cukup eksponensial, penggunaan Artificial Intelligence dalam bidang arsitektur dimungkinkan bukan hanya sebagai alat perpanjangan tangan dari arsitek tetapi juga perpanjangan otak yang dapat mengeksplorasi desain dengan lebih banyak pilihan dalam waktu yang lebih cepat secara efektif dan efisien.
\end{abstract}

Kata Kunci: Teknologi digital, perencanaan, perancangan, Artificial Intellegence

Abstract: The development of information technology in modern times touches every aspect of life that makes things easier and more practical. This situation also illustrates what happens in the field of architecture that demands an increase in perancangan complexity that is higher with a faster time than previous times. The use of digital technology in modern times in the field of architecture is slowly beginning to shift the traditional ways in the architectural planning and perancangan process. This paper aims to examine the role of digital technology using Artificial Intelligence in today's architectural planning and design processes so as to make the design process faster, easier, and more practical and provide more diverse options for architects to make design decisions. The method used in this paper is to analyze the literature from several related studies on planning and perancangan theory as well as Artificial Intelligence. With a fairly exponential development, the use of Artificial Intelligence in Architecture is not only extended hand as a tool but alsoextended brain that can explore designs with more options in a more effective and efficient.

Keywords: Digital technology, planning, perancangan, artificial intelegent 


\section{Pendahuluan}

Sebagai seorang arsitek, kita secara sadar atau tidak, dalam melakukan proses desain arsitektur dibagi menjadi dua tahapan besar yaitu perencanan dan perancangan. Tahapan pertama adalah perencanaan yang merupakan suatu sarana untuk mentransformasi persepsi-persepsi awal yang diterima oleh Arsitek tentang kondisi lingkungan ke dalam suatu rencana yang dapat dilaksanakan dengan teratur [1] dan dapat mendefinisikan tindakan-tindakan yang tersistematik dan terstuktur di masa depan [2]. Tahapan selanjutnya adalah perancangan, yang merupakan proses pengambilan keputusan dari informasi-informasi dan ketidakpastian yang ada dalam tahap sebelumnya, melalui tindakan-tindakan yang tegas agar tidak terjadi kekeliruan [3] dan berusaha menemukan bagian fisik yang tepat dari sebuah struktur fisik [4].

Perkembangan teknologi digital yang semakin mutakhir saat ini perlahan-lahan mengubah cara manusia dalam menjalani kehidupannya. Keadaan ini juga tercermin dalam bidang arsitektur. Penggunaan teknologi digital ini mengubah cara arsitek dalam melakukan proses desain arsitektur terlebih dengan kemajuan teknologi digital yang sangat signifikan dari tahun-tahun sebelumnya [5]. Transformasi yang cukup lambat ini sebenarnya telah dimulai sejak revolusi industri dengan munculnya teknik konstruksi modular dan prefabrikasi yang cukup baru pada saat itu, kemudian dikembangkannya perangkat lunak untuk menggambar agar proses penggambaran lebih cepat, dan akhirnya di masa kini dengan diperkenalkannya kemampuan komputasi statistik seperti ilmu data dan kecerdasan buatan [6]. Perubahan ini tidak hanya dalam proses penggambaran, tetapi juga dalam proses berpikir dari arsitek.

Makalah ini bertujuan untuk mengkaji peranan teknologi digital yang semakin signifikan sejak diperkenalkannya kemampuan komputasi dengan menggunakan kecerdasan buatan. Penggunaan kecerdasan buatan memungkinkan penggunaan teknologi digital saat ini tidak hanya untuk menggambar sebagai perpanjangan tangan, tetapi juga dapat menjadi alat untuk berpikir sebagai perpanjangan otak. Dengan demikian proses perencanaan dan perancangan desain dapat menjadi lebih cepat, mudah, dan praktis serta memberikan pilihan-pilihan yang lebih beragam bagi arsitek untuk menentukan keputusan desain.

\section{Tinjuan Pustaka}

Hingga saat ini hubungan antara perencanaan / pemrograman dan perancangan masih terdapat kontroversi [7]. Adanya perbedaan pendapat tentang sama atau berbedanya antara pemrograman dan perancangan, menjadikan bahwa programing atau pemrograman adalah perancangan, tetapi bagi sebagian arsitek lainnya berpendapat bahwa pemrograman tidak sama dengan perancangan. Menurut Edward T. White (1983) pemrograman adalah persiapan untuk merancang. Di lain pihak, Palmer (1981) mengatakan bahwa pemrograman merupakan aspek analisis dari perancangan. Dalam proses desain, Pena \& Parshall (2001) berpendapat bahwa terdapat dua proses yaitu analisa dan sintesa atau bisa dikatakan bahwa analisa adalah merupakan pemrograman dan sintesa adalah merupakan perancangan.

\section{Pemrograman}

Sebelum kita dapat memulai untuk mendesain suatu bangunan sebagai cara untuk memecahkan permasalahan (problem solving) pertama kita harus melakukan pencarian masalah (problem seeking). Dalam proses pencarian masalah yang termasuk dalam proses perencanaan atau bisa kita sebut pemrograman yang merupakan fase pertama dalam sebuah proyek arsitektur, agar arsitek dapat menetapkan tindakan atau perlakuan apa yang tepat di masa depan secara sistematik [2]. Menurut Shrode (1974), perencanaan dapat diartikan sebagai sarana untuk mengubah persepsi kondisi lingkungan menjadi rencana yang baik sehingga dapat dilakukan secara teratur [8].

William L. Lassey dalam bukunya yang berjudul Planning in Rural Environments berpendapat bahwa perencanaan adalah proses menyusun konsep dasar suatu rencana yang didalamnya terdapat beberapa kegiatan, diantaranya : yang pertama adalah mengidentifikasi yaitu dengan mengetahui dan memutuskan bagian mana yang menunjang dari objek, yang kedua adalah dengan mengadakan sutdi yaitu dengan melakukan survei untuk mencari hubungan antara faktor-faktor terkait yang memiliki dampak tertentu, kegiatan selanjutnya adalah dengan mendeterminasi dengan memutuskan 
dengan tepat faktor-faktor apa saja yang dominan, yang keempat adalah memprediksi atau meramalkan bagaimana suatu faktor dapat berubah menjadi lebih baik di masa depan, dan yang terakhir adalah dengan menerapkan langkah-langkah terstruktur untuk mencapai tujuan pembangunan [9].

Menurut Pena \& Parshall (2001), bangunan yang baik tidak terjadi begitu saja, tetapi direncanakan untuk terlihat dan bekerja dengan baik yang berasal dari arsitek dan klien yang baik dengan adanya usaha kooperatif dalam prosesnya. Dalam suatu proses perancangan arsitektur hal yang utama dan seringkali merupakan paling penting adalah dengan memprogram persyaratan bangunan [10]. Pemrograman mendahului desain sama seperti analisis mendahului sintesis. Pemisahan antara pemrograman dan desain sangat penting untuk mencegah terjadinya trial-and-error perancangan.

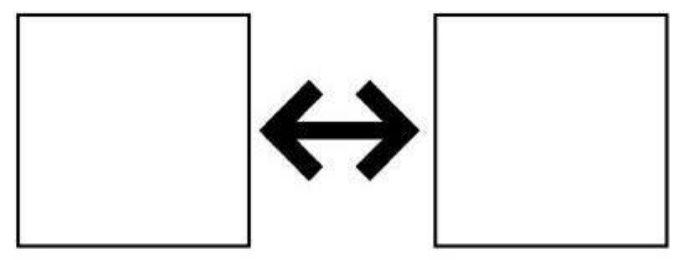

Programming

Design

Gambar 1. Pemisahan antara pemrograman and perancangan

[10]

Dalam melakukan pemrograman baik yang diperuntukan untuk bangunan rumah tinggal yang sederhana maupun bangunan kompleks seperti rumah sakit, terdapat lima langkah dasar yang diikuti oleh empat pertimbangan. Lima prinsip dasar tersebut adalah tujuan, fakta, konsep, kebutuhan, dan permasalahan yang diikuti oleh pertimbangan yaitu fungsi, bentuk, ekonomi, dan waktu [10].

Tabel 1. Lima langkah dan empat pertimbangan pemasalahan [10]

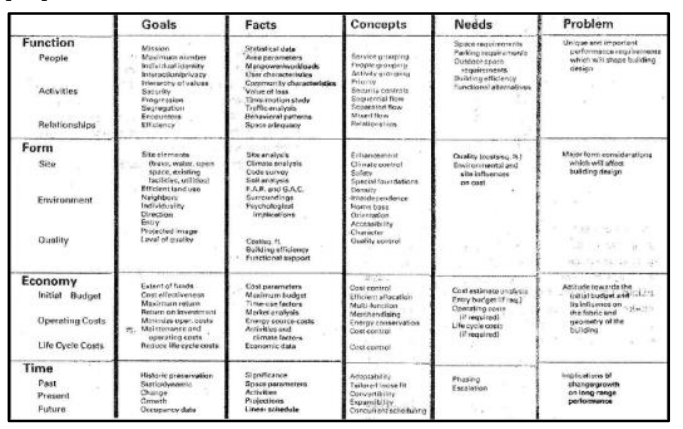

Seorang arsitek yang baik dan berpengalaman akan mencoba untuk menahan suatu penilaian dengan melakukan anallisis dan menolak solusi yang terbentuk dari sintesis sebelum semua informasi diterima dan dicari akar permasalahannya. Mereka percaya pada proses analisis secara menyeluruh sebelum melakukan sintesis. Menurutnya pemrograman adalah awal dari proses desain yang baik dan sudah melakukan setengah perjalanan dari keseluruhan proses desain, walaupun itu tidak menjamin.

\section{Perancangan}

Perancangan dalam hal ini adalah berusaha untuk mengolah fakta-fakta yang ada dengan tindakan yang berujung dengan ditemukannya komponen fisik yang sesuai dalam penyelesaian masalah terhadap fakta-fakta tersebut.

Bryan Lawson (1980) dalam bukunya yang berjudul "How Perancanganers Think : The Perancangan Process Demystified" mengidentifikasi bahwa ada lima fase dalam proses kreatif seorang perancang, yaitu : first insight, preparation, incubation, illumination, and verification.

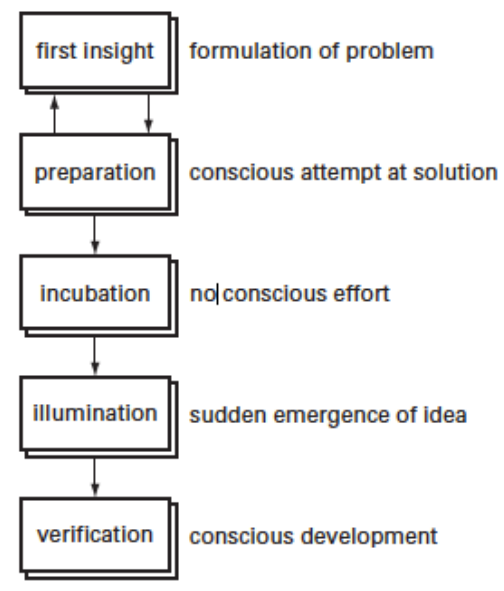

Gambar 2. Lima langkah kreatif proses [11]

Menurut John Wade (1977), desain adalah usulan utama untuk memperbaiki sesuatu yang sudah ada melalui tiga proses: mengidentifikasi masalah, menetapkan solusi untuk masalah, dan menerapkan pemecahan masalah. Proses tersebut dapat juga disebut sebagai pemograman, penyusunan rancangan, dan pelaksanaan rancangan. Pemrograman dimaksudkan untuk mengidentifikasi tujuan, kebutuhan, dan perhatian klien. Perencanaan 
adalah tentang merumuskan masalah klien secara keseluruhan sehingga menjadi masalah standar yang dapat dipecahkan dengan mudah. Sedangkan desain mengembangkan keseluruhan ide menjadi suatu bentuk konstruksi [12].

J.C. Jones (1990) dalam bukunya yang berjudul Development in Design Methodology berpendapat bahwa terdapat 3 fase perancangan yang terjadi sampai saat ini. Fase pertama adalah fase Craftmanship dimana sebuah rancangan yang dibuat dengan mengandalkan kreativitas atau seni (art) saja dari sang desainer. Fase kedua adalah fase Draughmantship dimana perencanaan yang berdasarkan gambar, hal ini dapat dicapai dengan mengukur suatu ukuran atau dimensi dengan ukuran tertentu, bentuk yang jelas dan dapat dilakukan dalam jumlah banyak atau dapat direalisasikan kembali. Fase ketiga adalah fase Design Methode yang terdiri dari Blackbox Design Methode (traditional) dan Glassbox Design Methode (rasional) [13].

Pada Blackbox Design Methode, desain dilakukan secara spontan oleh perancang karya. Ide bisa datang dari mana saja dan menghasilkan karya kapan saja. Sedangkan Glassbox Design Methode, merupakan perencanaan dilakukan secara rasional dan logis oleh perancang. Konsep desain yang dilakukan dalam beberapa tahapan dilakukan dengan memikirkan hal-hal tertentu dan tidak datang secara spontan.

\section{Teknologi dalam Arsitektur}

Praktek arsitektur yang sudah mulai menggunakan teknologi digital, juga tidak dapat lepas dari perkembangan teknologi yang semakin signifikan di masa sekarang ini. Pemanfaatan teknologi dalam dunia arsitektur yang cukup lambat dimulai sejak ditemukannya teknik konstruksi baru di awal masa modern. Kemudian perkembangan tersebut beralih dengan memanfaatkan teknologi digital dengan menggunankan perangkat lunak dan kemudian pada saat ini akhirnya penggunaan teknologi dalam arsitektur mulai menggunakan komputasi statistik (ilmu data dan kecerdasan buatan). Stanislas Chaillou (2018) dalam thesisnya di Harvard membagi empat periode perkembangan teknologi dalam arsitektur di masa modern ini.

Walaupun penggunaan komputer dalam bidang arsitektur telah berkembang pesat dibandingkan tahun-tahun sebelumnya, namun penggunaan komputer dalam arsitektur masih sebatas komputerisasi, artinya proses perancangan dilakukan oleh arsitek sendiri dan komputer hanya sebagai alat bantu untuk untuk mewakili dan merepresentasikan konsep [14]. Sementara itu, penggunaan algoritma sebagai proses untuk membuat solusi proyek dengan menggunakan metode matematis atau logika masih terbatas dan belum banyak digunakan.

Penggunaan algoritma sebagai proses untuk menghasilkan solusi desain menggunakan metode matematis atau logika masih terbatas dan belum banyak digunakan [14]. Dalam proses desain arsitektur, desain skrip algoritmik dikembangkan oleh Kostas Terzidis dan mulai membuat bentuk dan ruang menggunakan algoritma logika yang terkait dengan proses pemrograman arsitektur, jenis, kode arsitektur, dan bahasa itu sendiri.

\section{Metode Penelitian}

Metode yang digunakan dalam penelitian artikel ini adalah literature review yang akan dilakukan dengan menganalisa literatur dari beberapa buku, jurnal terpublikasi, dan penelitian terkait tentang teori perencanaan dan perancangan serta Artificial Intellegence. Dari literatur-literatur tersebut akan dikelompokkan menjadi tiga bagian yaitu perencanaan atau pemrograman, desain atau perancangan, dan Artificial Intelligence.

\section{Pembahasan Hasil \\ Evolusi Teknologi dalam Arsitektur}

Pengaruh perkembangan teknologi yang cukup pesat pada masa modern ini memaksa perubahan paradigma dalam memandang dunia ini. Banyak hal yang satu persatu mulai di digitalkan tanpa ada bentuk fisiknya sebagai upaya untuk menjadikannya lebih efektif dan efeisien.

Perkembangan arsitektur di masa modern ini terkait praktek arsitektur, metode, tradisi dan pengetahuannya menjadi bahan perbincangan yang tidak ada habisnya. Para praktisi sedang mencoba untuk meragukan perubahan yang sangat pesat ini dengan menjadikan teknologi digital sebagai masa depan dalam bidang arsitektur. Penggunaan teknologi digital ini mengubah cara arsitek dalam melakukan proses desain arsitektur terlebih dengan kemajuan teknologi digital yang sangat signifikan dari tahun-tahun sebelumnya.

Pada masa modern arsitektur yang dimulai sekitar awal abad 20an sebelum muncul era teknologi digital ini sebenarnya arsitektur sudah memulai transformasi yang cukup lambat yaitu sejak 
munculnya pembaharuan dengan adanya revolusi industri sehingga memunculkan teknik konstruksi baru yang kemudian dengan mulai dikembangkannya perangkat lunak yang memadai, dan akhirnya di masa kini dengan diperkenalkannya kemampuan komputasi statistik seperti ilmu data dan kecerdasan buatan [6]. Perubahan ini tidak hanya dalam proses penggambaran, tetapi juga dalam proses berpikir dari arsitek. Transformasi yang terjadi dalam bidang arsitektur pada masa modern ini telah membawa arsitektur secara berkesinambungan dalam evolusi teknologi yang berurutan dan sangat bermanfaat bagi perkembangan praktek desain dalam dunia arsitektur.

Evolusi tersebut dimulai dengan adanya teknologi konstruksi baru dengan penggunaan bahan prefabrikasi yang berupa modul-modul tipikal. Grid modular tersebut membawa harapan kesederhanaan teknis dan keterjangkauan.

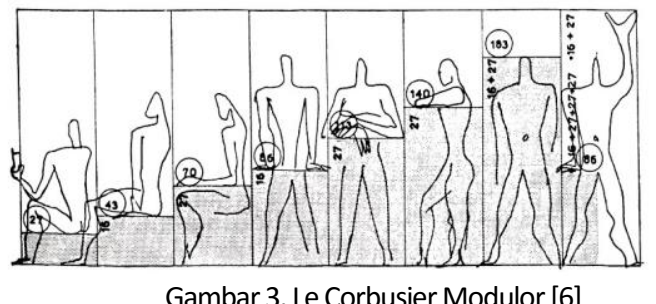

Selanjutnya masuk ke dalam era teknologi digital dengan penggunaan teknologi komputer sebagai sebagai alat untuk presentasi dalam proses penggambaran desain arsitektur. Semakin berkembangnya pengetahuan tentang bentuk arsitektur, muncul bentu-bentuk yang jauh lebih kompleks dari sebelumnya. Beberapa arsitek seperti Frank Gehry, Zaha Hadid, Patrick Schumacher, mencoba untuk memperkenalkan penggunaan parameter-parameter dengan mengkomunikasikannya ke dalam perangkat lunak sambil mengisolasi parameter utama yang memengaruhi hasil. Paradigma desain dengan menggunakan parameter ini juga disebut Parametricism [14].

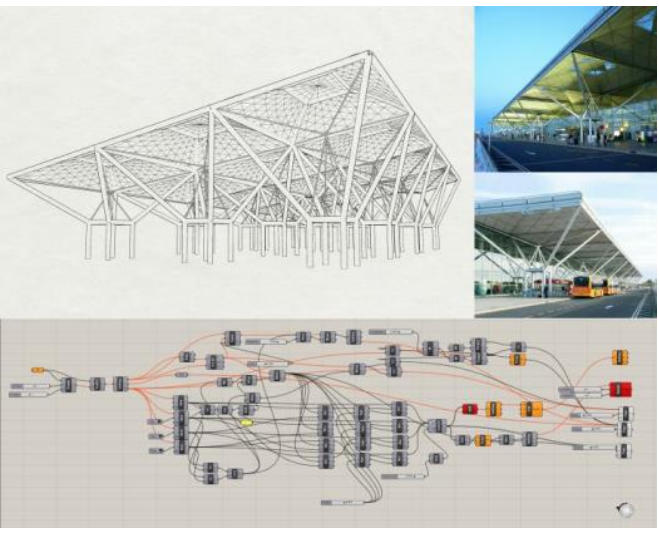

Gambar 4. Desain 3D menggunakan software parametric [14]

Terlepas dari kehebatan pengolahan bentuk yang kompleks dan perkembangan desain parametrik yang cukup signifikan dalam jangka waktu sekitar 10 tahun, terdapat beberapa kekurangan yang tidak dapat dilakukan oleh parametricism. Dalam kenyataannya, arsitektur merupakan hasil dari sejumlah parameter tetap yang disandikan oleh arsitek terkait konteks, linkgungan, sosial, budaya, dan sejarahnya yang dalam parametricism diabaikan kekompleksitasannya tersebut. Realitas yang dalam ini menggabungkan disiplin-disiplin ilmu dengan parameter-parameter yang sangat kompleks tersebut dengan cara yang sistemik yang di masa kini dapat kita lakukan dengan menggunakan kecerdasan buatan.

\section{Artificial Intelligence sebagai pendekatan baru}

Penggunaan Artificial Intelligence dalam bidang komputer bukanlah merupakan hal baru. John McCarthy pada tahun 1956 telah menciptakan konsep tentang Artificial Intelligenceini. McCarthy mendefinisikan Artificial Intelligence sebagai "menggunakan otak manusia sebagai model logika untuk mesin" [15]. Tidak seperti model komputer sebelumnya yang dibangun dengan dengan sejumlah variabel dan aturan, Artificial Intelligence memungkinkan komputer menghasilkan parameter informasi perantara, baik yang dikumpulkan dari data atau dikirimkan oleh pengguna. Setelah "tahap pembelajaran" tercapai, mesin dapat menghasilkan solusi, tidak hanya menanggapi serangkaian parameter yang telah ditentukan, tetapi menghasilkan konsekuensi yang meniru distribusi statistik informasi yang disajikan pada tahap pembelajaran. "Pembelajaran" yang dimaksud disini adalah pembelajaran yang dipahami oleh mesin yang sesuai dengan kemampuan komputer ketika dihadapkan pada masalah yang rumit, pertama 
adalah untuk memahami kompleksitas opsi yang ditunjukkan kepadanya dan kedua membangun "intuisi" untuk memecahkan masalah yang dipertaruhkan [16].

Konsep yang diciptakan oleh McCarthy inilah yang menjadi inti dari perubahan paradigma yang disebabkan oleh Artificial Intelligence. Kemandirian parsial dari mesin untuk menciptakan pemahamannya sendiri tentang suatu permasalahan dan kemampuannya untuk mencerna serangkaian contoh yang cukup kompleks, membalikkan premis Parametrikisme yang hanya mengikuti parameterparameter yang telah ditentukan oleh pengguna. Karena pengguna tidak secara eksplisit menyatakan semua aturan dan parameter, penggunaan Artificial Intelligence dapat secara tidak terduga mendeteksi fenomena yang mendasarinya dan bahkan mencoba menirunya. Dalam bidang komputasi, ini merupakan lompatan kuantum dari dunia heuristik (pengambilan keputusan berbasis aturan) ke dunia statistik (pengambilan keputusan stokastik) [17].

Walaupun perkembangan penggunaan komputer dalam arsitektur saat ini sudah jauh lebih maju dari pada tahun-tahun yang lalu, tetapi dominasi penggunaan komputer dalam arsitektur saat ini masih dapat diidentifikasi sebagai komputerisasi, yaitu di mana entitas atau proses yang sudah dikonseptualisasikan dalam pikiran perancang dimasukkan, disajikan, atau disimpan dalam sistem komputer. Sebaliknya, algoritma, sebagai proses pembuatan solusi desain dengan menggunakan metode matematis atau logis, umumnya terbatas. Sementara penelitian dan pengembangan perangkat lunak itu sendiri melibatkan teknik algoritmik yang luas, sedangkan manipulasi model komputer 3D berbasis mouse pada layar komputer tidak selalu merupakan proses algoritmik [18].

Menurut Kostas Terzidis (2002), saat ini arah baru untuk untuk algorithmic design sedang dirumuskan. Ini melibatkan penggunaan algoritma untuk menghasilkan ruang dan bentuk yang berasal dari logika berbasis aturan yang melekat pada program arsitektur, tipologi, peraturan bangunan dan bahasa itu sendiri. Alih-alih menggunakannya sebagai pemrograman langsung, kodifikasi desain skrip algoritma yang dibangun di atas sistem pemodelan dapat membangun consistency, structure, coherency, traceability, and intelligence into computerized 3D form [19]. Desain algoritmik ini adalah kerangka kerja konseptual untuk eksplorasi bentuk, struktur, dan proses desain arsitektur. Ini menggabungkan teori dan metode ilmu komputer serta ruang desain abstrak yang diwujudkan dalam pemodelan dan sistem animasi saat ini [14].
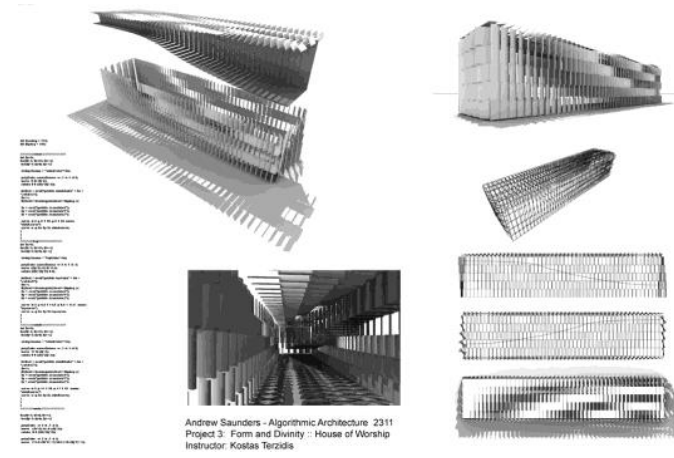

Gambar 5. House of Worship : an ambiguous algorithmic structure perancangan by GSD student Andrew Sanders [14]

Penggunaan algoritma dalam Artificial Intelligence ini menjadi lebih menarik dengan ide yang awalnya diteorikan oleh lan Goodfellow, yang merupakan seorang peneliti di Google Brain, pada tahun 2014, model ini menawarkan penggunaan jaringan untuk menghasilkan gambar dan memastikan akurasi melalui umpan balik yang mengoreksi sendiri. Algoritma ini dinamakan Generative Adversarial Neural Networks (GANs) [20]. Penelitian Goodfellow membalikkan definisi Artificiaal Intelligence, dari alat analisis menjadi agen generatif. Dengan cara yang sama, dia membawa Artificiaal Intelligence selangkah lebih dekat ke dalam dunia arsitektur: menggambar dan produksi gambar. Secara keseluruhan, dari jaringan sederhana hingga GAN, alat generasi baru yang digabungkan dengan daya komputasi yang semakin murah dan dapat diakses kini memposisikan Artificiaal Intelligence sebagai media yang terjangkau dan kuat [21].

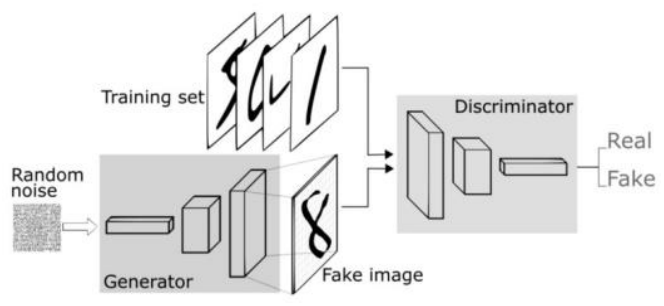

Gambar 6. Algoritma dari GAN [6]

\section{Pengembangan Artificial Intelligence dalam Arsitektur}

Dalam melakukan proses desain arsitektur, dibagi menjadi dua tahapan besar yaitu perencanan dan perancangan, kegiatan-kegiatan tersebut dilakukan sepenuhnya oleh kesadaran alami manusia yang 
dalam hal ini adalah arsitek sebagai desainer itu sendiri. Sebagai tahap awal dari proses desain yaitu pencarian masalah, perencanaan atau pemrograman merupakan scientific approach yang terstruktur dan membutuhkan waktu yang tidak sebentar karena arsitek dituntut untuk mentransformasikan persepsipersepsi tentang kondisi lingkungan di masa sekarang dengan perencanaan yan tepat dan dapat dilaksanakan secara teratur di masa depan. Selanjutnya merupakan tahap perancangan yang menjadi creative process dari seorang arsitek yang dilakukan setelah masalah dari fakta-fakta telah ditemukan dan kemudian di analisa (pemrograman) untuk selanjutnya di sintesa (perancangan) sehingga dapat menghindari terjadinya trial-and-error perancangan [22].

Berbasiskan model otak manusia sebagai model logika untuk mesin, dengan menggunakan Artificial Intelegent, pemrograman and perancangan dapat dilakukan oleh mesin yang dapat belajar dari informasi-informasi yang dikumpulkan dari data dan juga yang dikirim oleh pengguna. Proses pemrograman yang merupakan scientific approach dalam tahap awal perencanaan seperti identifikasi, studi, determinasi, prediksi dan tindakan terstruktur dapat dilakukan oleh mesin dengan perhitungan dan algoritma yang lebih detail dan terstruktur sehingga membuat proses tersebut lebih efektif dan efisien. Creative proses yang sebelumnya juga dilakukan oleh manusia yang memiliki rasa dan imajinasi juga dapat dilakukan oleh mesin dengan berbasis pada langkah yang telah ditentukan sebelumnya seperti first insight, preparation, incubation, illumination, and verification menjadi lebih cepat dan menghasilkan banyak alternative desain dengan menggunakan algoritma-algoritma yang di input oleh arsitek.

\section{Kesimpulan}

Penggunaan Artificiaal Intelligence dalam berbagai bidang seperti komputer, kesehatan, robotika dan beberapa bidang lainnya sudah sangat maju, tetapi dalam bidang arsitektur penggunaan Artificiaal Intelligence belum terlalu banyak digunakan secara menyeluruh. Dalam bidang arsitektur proses perencanaan dan perancangan masih dilakukan secara manual oleh manusia, dan teknologi digital masih digunakan sebatas perpanjangan tangan sebagai alat untuk penggambaran. Semakin majunya perkembangan Artificial Intelligence dalam bidang lain semakin banyak pula peneliti dalam bidang arsitektur yang mencoba mengeksplorasi Artificial
Intelligence lebih jauh ke dalam arsitektur. Berdasarkan literatur yang dibahas pada artikel ini, proses perencanaan dan perancangan dalam arsitektur dapat menjadi bagian yang terhubung dengan penggunaan Artificial Inteliigence. Kemungkinan penggunaan teknologi ini bukan hanya sebatas sebagai alat perpanjangan tangan dari arsitek tetapi perpanjangan otak yang dapat mengeksplorasi desain dengan lebih banyak pilihan dalam waktu yang lebih cepat secara efektif dan efisien.

\section{Pustaka}

[1] E. T. White, "Site Analysis: Diagramming Information for Architectural Design," United States Am., pp. 235-237, 1983.

[2] P. Davidoff and T. A. Reiner, "A Choice Theory of Planning," J. Am. Plan. Assoc., vol. 28, no. 2, pp. 103-115, 1962, doi: 10.1080/01944366208979427.

[3] M. Asimow, Introduction to design. Los Angeles: Prentice-Hall, 1964.

[4] C. Alexander, Ingrid, Sara, and Peter, "The Timeless Way of Building Complete.pdf." 1979.

[5] M. G. Gunagama and N. F. Lathifa, "Automatictecture : Otomatisasi Penuh Dalam Arsitektur Masa Depan," NALARs, vol. 16 , no. 1 , p. 43,2017 , doi: 10.24853/nalars.16.1.43-60.

[6] S. Chaillou, "The Advent of Architectural Al A Historical Perspective," Towar. Data Sci., pp. 1-17, 2019.

[7] W. N. Nurwarsih, "Korelasi Kebutuhan Fungsi Terhadap Proses dan Program Perancangan Arsitektur," J. UNDAGI, vol. 5, no. 2, pp. 1926, 2017, [Online]. Available: https://ejournal.warmadewa.ac.id/index.php /undagi/article/.../297\%0A\%0A.

[8] W. A. Shrode and D. Voich, Organization and Management: Basic Systems Concepts.

Michigan: R. D. Irwin, 1974.

[9] W. R. Lassey, Planning in Rural Environments. New York: McGraw-Hill, 1977.

[10] W. M. Peña and S. a. Parshall, Problem Seeking, Fourth. New Jersey: John Wiley \& Sons, 2001.

[11] P. Purcell, "How designers think," Des. Stud., vol. 2, no. 1, pp. 55-56, Jan. 1981, doi: 10.1016/0142-694X(81)90033-8.

[12] J. W. Wade, Architecture, Problems, and 
Purposes: Architectural Design as a Basic Problem-solving Process. Wiley, 1976.

[13] J. C. Jones, Design Methods. Wiley, 1992.

[14] K. Terzidis, "The nature of computation Algorithmic Design: A Paradigm Shift in Architecture?," pp. 201-207, 2002, [Online]. Available: http://www.bol.ucla.edu/ kostas/.

[15] J. McCarthy, "The Philosophy of Al and the Al of Philosophy," Philos. Inf., pp. 711-740, 2008, doi: 10.1016/B978-0-444-517265.50022-4.

[16] J. Pearl, Heuristics: Intelligent Search Strategies for Computer Problem Solving. Addison-Wesley Publishing Company, 1984.

[17] S. Mirshekarian and D. Sormaz, "Machine Learning Approaches to Learning Heuristics for Combinatorial Optimization Problems," Procedia Manuf., vol. 17, pp. 102-109, 2018, doi: 10.1016/j.promfg.2018.10.019.

[18] J. A. Grisaleña, "Digital Design Strategies: Ways To Think, Conceive and Implement the Digital in Architectural Design," pp. 1-19, 2017.

[19] K. Terzidis, Expressive form: A conceptual approach to computational design. 2003.

[20] I. Goodfellow et al., "Generative adversarial networks," Commun. ACM, vol. 63, no. 11, pp. 139-144, 2020, doi: 10.1145/3422622.

[21] C. Uzun, M. B. Çolakoğlu, and A. İnceoğlu, "GAN as a generative architectural plan layout tool: A case study for training DCGAN with Palladian Plans and evaluation of DCGAN outputs," vol. 17, no. 2, pp. 185-198, 2020, doi: 10.5505/itujfa.2020.54037.

[22] A. K. Wisler, "'Of, by, and for are not merely prepositions': teaching and learning Conflict Resolution for a democratic, global citizenry," Intercult. Educ., vol. 20, no. 2, pp. 127-133, 2009, doi: 10.1080/14675980902922143. 